\title{
Voltage Stability Assessment of Radial Distribution Systems Including Optimal Allocation of Distributed Generators
}

\author{
Ali Selim ${ }^{1,2}$, Salah Kamel2,3, Loai S. Nasrat², Francisco Jurado ${ }^{1 *}$ \\ ${ }^{1}$ Department of Electrical Engineering, University of Jaén, 23700 EPS Linares, Jaén (Spain) \\ ${ }^{2}$ Department of Electrical Engineering, Faculty of Engineering, Aswan University, 81542 Aswan (Egypt) \\ ${ }^{3}$ State Key Laboratory of Power Transmission Equipment and System Security and New Technology, \\ Chongqing University, Chongqing 400030 (China)
}

Received 24 March 2019 | Accepted 14 October 2020 | Published 18 February 2020

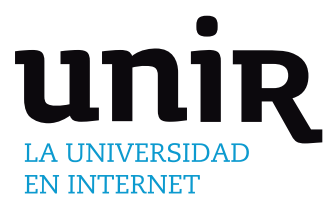

KEYWORDS

Whale Optimization Algorithm, Fuzzy Logic Controller, Voltage Stability Index, Optimal DG Placement.

\section{INTRODUCTION}

$\mathrm{R}$ ECENTLY, the complexity of the power system has been increased to align the expansion of the total load demand due to the economic and environmental constraints [1]. Power systems could be viewed as complex systems due to their structure which includes many types of components such as controlling, measuring, and monitoring devices. Hence, the increase of the load may lead to disturbance occurrence in the power system which brings an unallowable reduction in the voltage level and raises the probability of voltage instability which affects the power system operation.

Voltage stability is defined as the ability of the power system to keep the voltage of all buses at the acceptable range under abnormal conditions [1]. The probability of the voltage instability increases when there is no chance to recover the loads by the active or reactive power demand which causes the voltage collapse [2].

The voltage stability assessment has been considered as the main problem in power system monitoring [1] [3]. Considerable attention has been paid to determine maximum power system load ability limit before voltage collapse occurs [4] [5].

Voltage collapse is identified as a strongly decaying in the power system voltage level [2]. Voltage collapse could bring an unexpected

* Corresponding author.

E-mail address: fjurado@ujaen.es shortage in the power system. Some countries challenged the voltage collapse phenomenon such as France, Japan, Sweden, and Germany [6]. Correspondingly, voltage stability indices (VSIs) have been presented to identify the most sensitive bus in the system that can lead to voltage instability [7].

To overcome the voltage instability and voltage collapse problems, many studies have been proposed and presented [8] [9]. However, the integration of distributed generators (DGs) with the power system increases power system reliability and decreases power losses. Consequently, the best solution has been addressed in the literature and is to use the active and reactive power of the DG which is connected at a suitable location to operate systems with maximum economic and reliability and enhance the performance of power system [10]. Therefore, accurate indices are required by the power systems utilities to clarify the possibility of the voltage collapse occurring, then the utilities tend to use a compensation device such as a DG [8] [11].

Currently, several research works have been presented to optimally allocate DGs in the power system. Numerous optimization techniques have been used subjected to different objective functions to increase the advantages of DGs, for instance, power loss decline, voltage profile improvement, and voltage stability [12]. DG allocation problem using optimization can be classified into many different categories based on objective functions, constraints, and the type of algorithms [13].

Two main algorithms have been frequently used in the DG allocation problem [13]. The first algorithm is the analytical method, it is a simple method that implements a mathematical formulation to 
maximize or minimize an objective function by changing the main control variables [14]. Many analytical indices have been applied to allocate the DG into distribution systems. The minimization of power loss using an analytical technique was presented in [15]. Loss sensitivity factor (LSF) has been used to find the most sensitive bus in the system subject to the change in the active or reactive power [16]. Furthermore, the power stability index (PSI) and voltage stability index (VSI) have been introduced to integrate DG in the distribution network. These two stability indices have been applied to recognize the most sensitive buses which could cause instability with increasing the load [17].

The second algorithm is the metaheuristic optimization algorithm, which attempts to generate all possible solutions from an initial set of solutions. A genetic algorithm (GA) has been used to optimally place the DG in distribution system [18]. Particle swarm optimization has been applied in [19]. Cuckoo Search Algorithm (CSA) has been applied in references [20] [21] to decrease the power loss and improve the voltage profile. For the multiobjective optimization problem, and NSGA II has been introduced in [22] to simultaneously minimize the power loss and maximize the VSI. Metaheuristic optimization techniques are intelligent based optimization methods [23] [24]. The main advantage of the metaheuristic techniques is the ability to handle complex problems without going so far in the problem details [13]. However, these algorithms take an uncertain time of convergence based on the search space limits and may trap in the local optima [13].

To overcome the drawback of the metaheuristic optimization technique and decrease its search space, a hybrid optimization technique can be implemented. Hence, this paper presents a hybrid between analytical VSI and a modern heuristic optimization technique named Whale Optimization Algorithm (WOA). WOA proved its efficiency as a nature-inspired based technique in comparison to the other methods [25]. The VSI is mathematically formulated, then a fuzzy logic controller is implemented using the normalized VSI and voltage magnitude at each node to arrange the system buses according to the fuzzy weighting output. The highest output weighting buses are chosen to be the candidate buses to the DG placement. Finally, the WOA is used to compute the optimal location and size of injected active and reactive powers of the DG to minimize the total power losses. The MATLAB environment is used to formulate and evaluate the objective function. The DG influence on the voltage stability is traced with PV curve analysis that performed using the continuation power flow (CPF) using PSAT package. The developed method is tested on 12, 33, 69, and 85 radial distribution systems, the results prove that using the optimal allocation of the DG increases the voltage stability.

The paper structure is prepared as follows: Section II addresses the mathematical formulation of the problem which includes the objective function, VSI, fuzzy logic controller, and WOA. The optimization process of allocating DG is introduced in Section III. The simulation results and discussion based on the study test system are presented in Section IV. Finally, Section V presents the conclusion.

\section{Mathematical Problem Formulations}

In this section, the main objective function and the mathematical formulation for the VSI with the fuzzy logic controller and the metaheuristic WOA are presented.

\section{A. Objective Function}

In this paper, the main purpose of the DG connection in the distribution system is to reduce the power losses $P_{\text {loss }}$ hence, the objective function $F$ can be expressed as.

$$
F=\min \left(P_{\text {loss }}\right)
$$

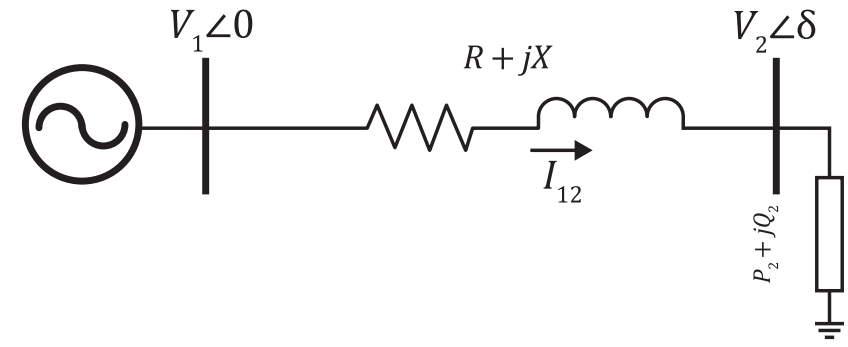

Fig. 1 Equivalent circuit model.

Where, for each two linked buses, $j$, the power loss $P_{\text {loss_z }}$ can be calculated using the resistance $R_{i j}$ and the current $I_{z}$ passing through the branch $z$ as follows:

$$
P_{\text {loss_z }}=R_{i j} I_{z}^{2}
$$

To calculate the overall active power loss in the distribution system, a summation of the losses in all system branches $n_{-} b r$ are added as follows:

$$
P_{\text {loss }}=\sum_{z=1}^{n_{-} b r} P_{\text {loss } \_}
$$

\section{B. Implementation of Voltage Stability Index VSI}

To obtain a mathematical formulation for VSI, simple implementation for the radial distribution system consists of two buses is used as presented in Fig 1. The figure shows that the power transfers from bus 1 (where the source is connected) over a transmission line have an impedance $\mathrm{R}_{12}+J X_{12}$ to the load connected at bus 2 . The load consuming active and reactive power $\mathrm{P}_{2}+J Q_{2}$.

In this case, the load current at bus 2 is the same branch current passing between 1 and 2 , hence the brach current $I_{12}$ is expressed as follows:

$$
I_{12}=\left[\frac{P_{2}+\mathrm{jQ}_{2}}{V_{2} \angle \delta}\right]^{*}
$$

Hence, the voltage $V_{2}$ can be calculated using the voltage $V_{1}$ and the voltage drop across the line as :

$$
V_{2} \angle \delta=V_{1} \angle 0-\left(\mathrm{R}_{12}+j X_{12}\right) I_{12}
$$

Using the current in (4) then eq (5) can be rewritten as:

$$
V_{2} \angle \delta=V_{1} \angle 0-\left(R_{12}+j X_{12}\right)\left(\frac{P_{2}-j Q_{2}}{V_{2} \angle-\delta}\right)
$$

Reorganize the eq (6) using multiplication with $V_{2} \angle-\delta$

$V_{2}{ }^{2}=\left(V_{1} V_{2} \cos (\delta)-j V_{1} V_{2} \sin (\delta)\right)-\left(R_{12}+j X_{12}\right)\left(P_{2}-j Q_{2}\right)$

Separate the real and imaginary parts

$V_{2}^{2}+P_{2} R_{12}+Q_{2} X_{12}=V_{1} V_{2} \cos \delta$

$P_{2} X_{12}-Q_{2} R_{12}=-V_{1} V_{2} \sin \delta$

$$
\begin{aligned}
& \text { Let } \delta \approx 0 \text { and } R_{12}=\frac{P_{2} X_{12}}{Q_{2}} \\
& V_{2}^{2}-V_{2} V_{1}+\left(\frac{P_{2}^{2}}{Q_{2}}+Q_{2}\right) X_{12}=0
\end{aligned}
$$

Equation (9) can be solved as a quadratic equation and for stable bus voltages condition, $b^{2-} 4 a c \geq 0$.

Finally, the VSI can be obtained as follows: 


$$
V S I=\frac{4 X}{V_{1}^{2}}\left(\frac{P_{2}^{2}}{Q_{2}}+Q_{2}\right) \leq 1
$$

For normal operation, the system can be considered a stable as long as the $V S I<1$. So, the system is more stable when the VSI value is close to zero. Consequently, the node with a maximum value of the VSI is the most sensitive node in the system and should be chosen as the optimal DG location.

\section{Candidate Buses Using the Fuzzy Logic Controller}

The candidate buses are arranged using a fuzzy logic controller. The fuzzy controller is implemented with two inputs and one output. The first input is NVSI and can be expressed as follows:

$$
N V S I_{i}=\frac{V S I_{i}-V S I_{\max }}{V S I_{\max }-V S I_{\min }}
$$

where all $\mathrm{NVSI}_{i}$ are between $[0,1]$.

Five membership functions are utilized to represent the NVSI as illustrated in Fig. 2.a. Also, the second input is the voltage profile at each node and represented with five membership functions as presented in Fig 2.b. The fuzzy output is calculated using predetermined rules based on (IF, Then). The output degree is shown in the surface plot in Fig. 3. Hence, each bus obtains a weighting value then these values are listed in descending order as a candidate bus.

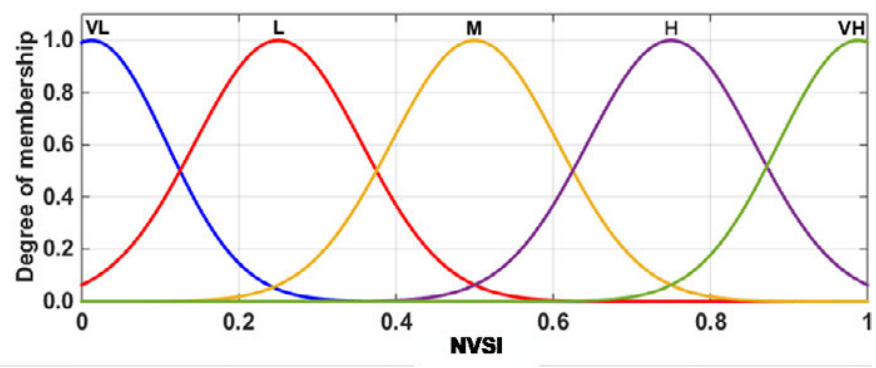

(a) Membership function for NVSI.

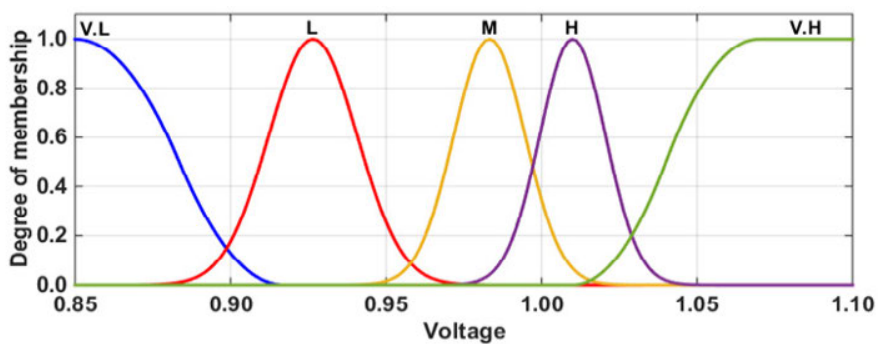

(b) Membership function for voltage magnitude.

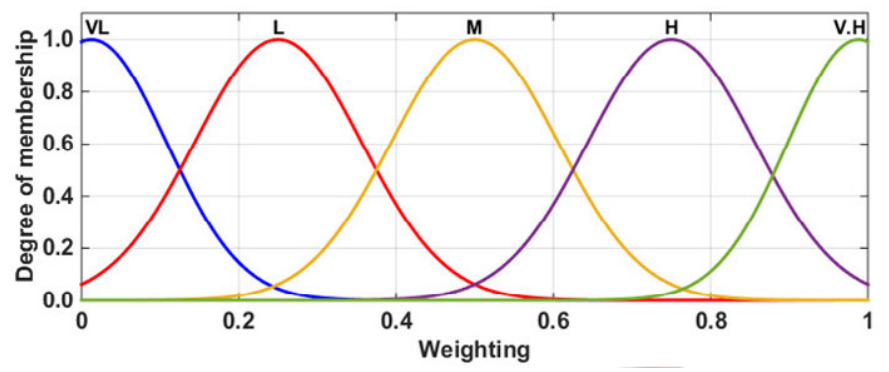

(c) Membership function for weighting.

Fig. 2. Fuzzy inputs and output memberships. (VL= Very Low, L= Low, $\mathrm{M}=$ Medium, $\mathrm{H}=$ High, and $\mathrm{VH}=$ Very High)

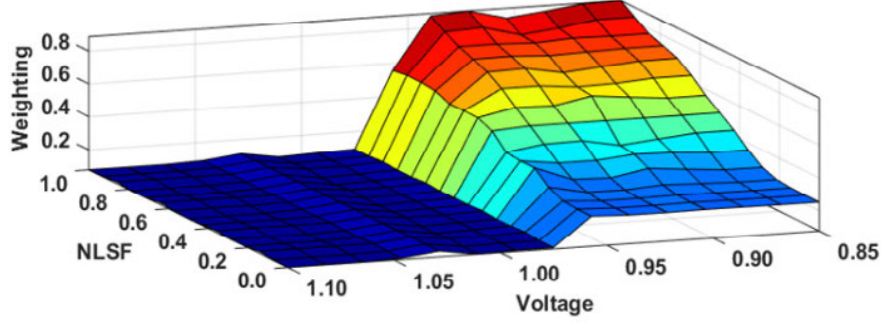

Fig. 3. Fuzzy rules output in 3 D plot.

\section{Overview of Whale Optimization Algorithm (WOA)}

WOA is a metaheuristic optimization technique that has been recently introduced by S. Mirjalili in [25]. The performance of WOA has been validated using 29 optimization benchmark functions and 6 structural design problems. Results show the efficiency of WOA in comparison with some nature-inspired algorithms [25]. In fact, the WOA simulates the hunting behavior of humpback whales. These whales are characterized by a bubble net feeding technique for hunting their prey.

In consequence, three stages have been utilized to mathematically represent the hunting procedure of the whales as described below:

\section{Search for Prey}

In order to imitate the random movement of the whales in case of their searching, a random search whale $X^{\text {rand }}$ is used to update the position of the whales as follows:

$$
\begin{aligned}
& X^{k+1}=X^{\text {rand }}-A . D \\
& D=\left|C \cdot X^{\text {rand }}-X^{k}\right|
\end{aligned}
$$

where, $X^{k}$ is the current position of the whale at iteration $k$, and $X^{k+1}$ is the updated position for the next iteration. $D$ represents the distance from the random search agent $X^{\text {rand }}$ to $X^{k}$.

$A$ is a random value with prespecified limits $[-a, a]$ where coefficient $a$ is reducing from 2 to 0 , then $A$ can be expressed with the following formula:

$$
\begin{aligned}
& A=2 \text { a.r }-a \\
& a=2-k\left(2 / K_{\max }\right)
\end{aligned}
$$

where, $r$ is a random number in the range of $[0,1]$, then $C$ can be computed as:

$$
C=2 \cdot r
$$

\section{Encircling Prey}

The mathematical formulation for encircling the prey by the whale can be adopted using the next equations:

$$
\begin{aligned}
& X^{k+1}=X^{*}-A . D \\
& D=\left|C \cdot X^{*}-X^{k}\right|
\end{aligned}
$$

The whales use a spiral-shaped in to encircle the prey, this shape can be mathematically presented as:

$$
\begin{aligned}
& X^{k+1}=D^{\prime} \cdot e^{b l} \cdot \cos (2 \pi l)+X^{*} \\
& D^{\prime}=\left|X^{*}-X^{k}\right|
\end{aligned}
$$

In this case, $D^{\prime}$ describes the absolute distance value between $X^{k}$ (current whale position) and the best position $X^{*} . b$ implements the formula of the logarithmic spiral. $l$ is a random number with a range $[-1,1]$. 


\section{Bubble Net Hunting}

Two whale movements have been used to formulate the bubble net hunting, the first movement uses the encircling prey by applying (17), where the second uses the spiral shape as described in (19). The transition between those two movements can occur using a random probability parameter $p$ as follows:

$$
X^{k+1}= \begin{cases}X^{*}-A \cdot D, & p<0.5 \\ D^{\prime} \cdot e^{b l} \cdot \cos (2 \pi l)+X^{*}, & p \geq 0.5\end{cases}
$$

The overall WOA is presented in the pseudocode shown in Fig. 4.

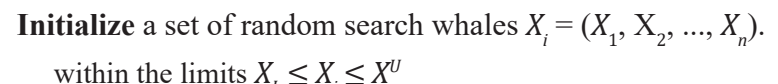

Calculate the objective function for each search whale

Store the best solution $X^{*}$

While $\left(k<K_{\max }\right)$

for each search whale $X_{i}$

Update the parameters $A, a$, and $C$ using (14), (15), and (16) respectively

$$
\begin{aligned}
& p=\text { rand } \\
& l=\text { rand }
\end{aligned}
$$

If $1 p<0.5$

If $2|\boldsymbol{A}|<1$

Update the whale's positions using (17), and (18)

else if $2|\boldsymbol{A}| \geq 1$

Choose a random whale $X^{\text {rand }}$

Update the whale's positions using (12), and (13)

end if 2

else If $1 p \geq 0.5$

Update the whale's positions using (19), and (20)

end if 1

Calculate the objective function

Update the best solution $X^{*}$

$K=K+1$

end while

return the final best solution stored $X^{*}$

Fig. 4. Pseudocode of WOA

\section{Voltage Stability Assessment with DG Allocation}

The assessment of the power system voltage stability with optimal allocation of the DG is described in the flowchart shown in Fig. 5. The overall process is concluded in the main following steps:

Step 1: Read the system data (line data and load data) and define the objective function.

Step 2: Run the power flow and obtain the voltage magnitude and angle for all buses.

Step 3: Compute the VSI for each node and calculate the $N V S I_{i}$.

Step 4: Apply the fuzzy logic controller to arrange the candidate buses.

Step 5: Randomly initialize a set of search whales with the candidate buses, WOA parameters, and Max. number of iterations $K_{\max }$.

Step 6: Run power flow and calculate the objective function for each search whale and store the best solution.

Step 7: For each search whale, update the parameters $a, A, C, I$ and $p$.
Step 8: Calculate the objective function for each search agent.

Step 9: Update the best solution.

Step 10: If $k<K_{\max }$, repeat Step 5 .

Step 11: Return the stored best solution obtained so far.

Step 12: Use the best solution as the optimal size and location for the DG.

Step 13: Run the continuation power flow and assess the power system voltage stability by tracing the PV curve.

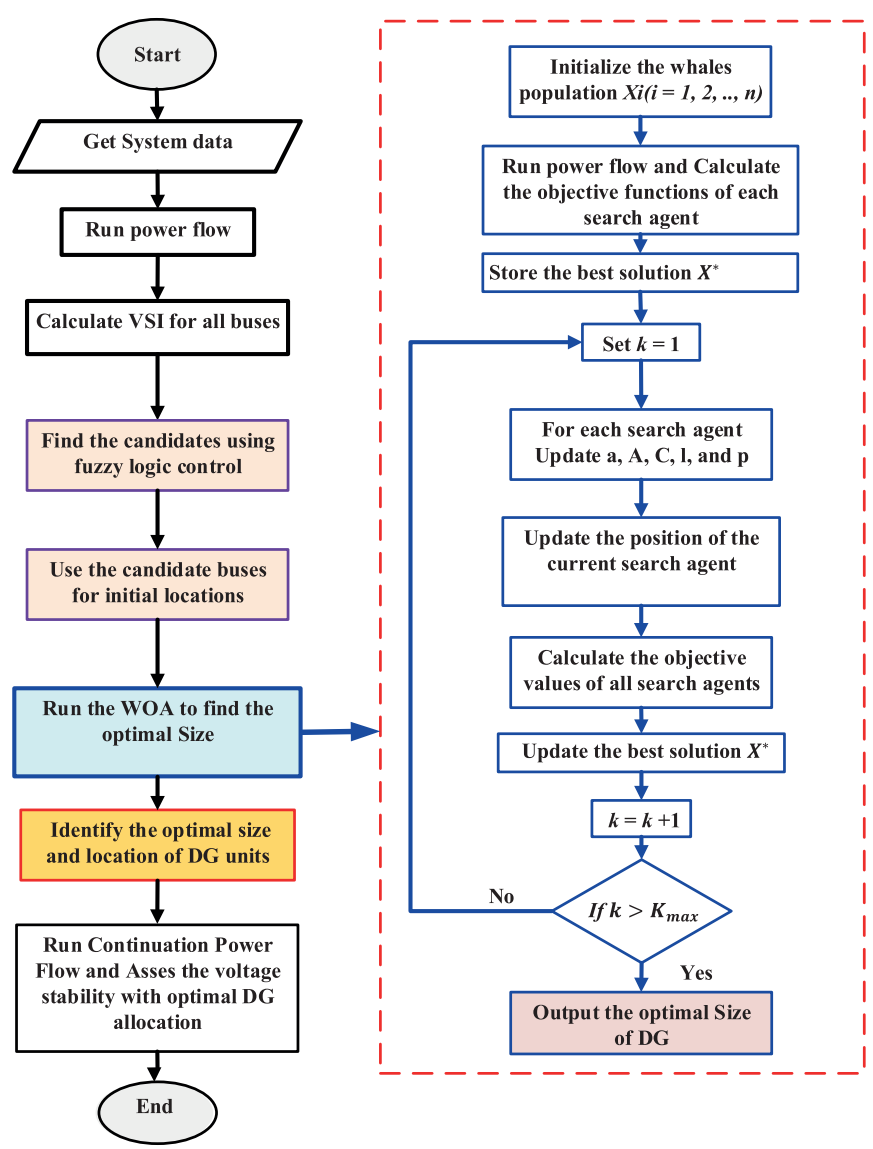

Fig. 5. Flowchart for voltage stability assessment with optimal DG allocation.

\section{RESUlts AND Discussion}

In this section, the performance of the proposed hybrid VSI and WOA technique is tested using $12,33,69$, and 85 radial distribution systems. The feasibility and efficiency of hybrid VSI and WOA to optimally allocate DG in radial distribution systems are proved compared with other well-known optimization techniques. All simulations have been carried out using MATLAB M-files. WOA parameters are set as; the number of agents $=100$, the maximum number of iterations $=50$. The following four cases have been considered for the DG allocation and voltage stability assessment in the studied systems:

1. Case 1: No DG unit is connected.

2. Case 2: One DG unit that injects only active power is connected.

3. Case 3: One DG unit that injects only reactive power s connected.

4. Case 4: One DG unit that injects active and reactive powers is connected.

\section{A. 12-bus Radial Distribution System}

The distribution system can be found in [26]. The system consists of 12 buses and 11 branches. The fuzzy logic controller using the NVSI 
and voltage profile is applied to the 12-bus system. Table I summarizes the ordering of the candidate buses. For each branch, VSI is calculated then the NVSI is adopted as the first input of the fuzzy logic controller. The voltage at the end of each branch bus is used as the second input as presented in the table. As seen in the table, branch 8 has the highest VSI and NVSI and it receives bus 9 that has 0.9473 p.u voltage. Respecting to the fuzzy rules this bus is considered the highest output hence, the fuzzy weighting output is 0.8210 . The same process is performed in all buses and the order of candidate buses is shown in Table I.

TABLE I. Candidate Bus Ordering Using Fuzzy Logic Control

\begin{tabular}{|c|c|c|c|c|c|c|}
\hline 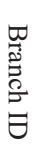 & 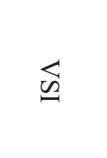 & 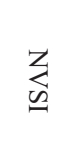 & 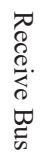 & 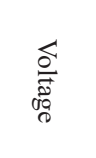 & 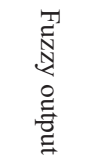 & $\begin{array}{l}\varpi \\
\tilde{\infty} \\
ᄋ \\
\stackrel{0}{0} \\
\stackrel{9}{\rho}\end{array}$ \\
\hline 1 & 0.00180 & 0.334 & 2 & 0.9943 & 0.0888 & 9 \\
\hline 2 & 0.00138 & 0.233 & 3 & 0.9890 & 0.0806 & 11 \\
\hline 3 & 0.00325 & 0.674 & 4 & 0.9806 & 0.0859 & 10 \\
\hline 4 & 0.00274 & 0.555 & 5 & 0.9698 & 0.1314 & 7 \\
\hline 5 & 0.00067 & 0.065 & 6 & 0.9665 & 0.1264 & 8 \\
\hline 6 & 0.00162 & 0.291 & 7 & 0.9637 & 0.2178 & 6 \\
\hline 7 & 0.00389 & 0.826 & 8 & 0.9553 & 0.6337 & 2 \\
\hline 8 & 0.00463 & 1.000 & 9 & 0.9473 & 0.8210 & 1 \\
\hline 9 & 0.00213 & 0.412 & 10 & 0.9445 & 0.4003 & 3 \\
\hline 10 & 0.00132 & 0.220 & 11 & 0.9436 & 0.2710 & 4 \\
\hline 11 & 0.00039 & 0.000 & 12 & 0.9434 & 0.2534 & 5 \\
\hline
\end{tabular}

\section{DG Allocation}

In the base case (Case 1), the power flow results of the 12-bus system indicate that the active and reactive power losses are 20.7138 $\mathrm{kW}$ and $8.0411 \mathrm{kVAR}$, respectively. The minimum voltage bus is reported at bus 12 with 0.9434 p.u. After applying the fuzzy logic controller using NVSI and the voltage magnitude, the WOA is applied to find the final size at the candidates' buses which give the minimum power loss.

Table II gives the optimal sizes and locations of three DG cases. For Case 2, the optimal size is calculated using the WOA and its value is $235.5 \mathrm{~kW}$, as shown in Table II, and the total power loss decreases to $10.774 \mathrm{~kW}$ with Loss Reduction (LR) reaching $47.98 \%$. The minimum voltage, in this case, is 0.9835 at bus 7 .

At Case 3, where 210.21 kVAR reactive power is injected at bus 9, the LR is $39.25 \%$ and the minimum voltage reports at bus 12 with 0.9563 p. u. A significant LR is obtained in Case 4 due to the active and reactive power injection. The LR is $84.76 \%$ and the minimum voltage bus is 7 with 0.9907 p.u. Overall enhancement in the voltage profile in the three cases is illustrated in Fig 6. A considerable enhancement is achieved at Case 4.

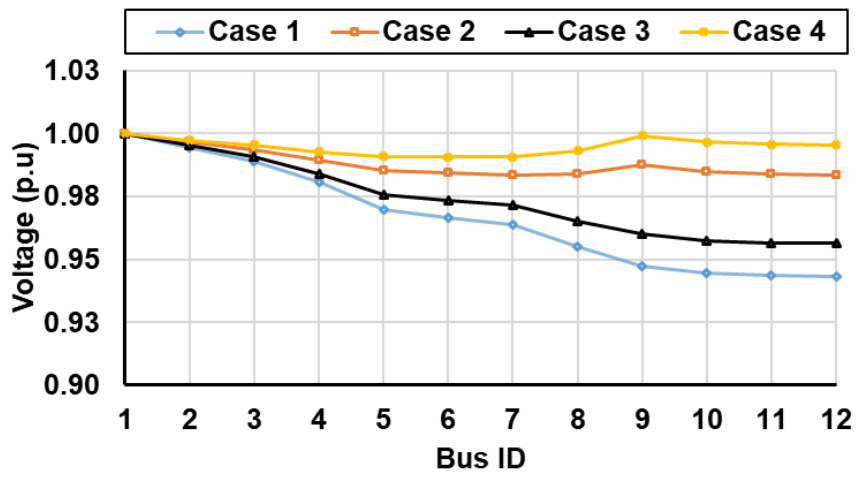

Fig. 6. Voltage profile of 12-bus at different case studies.
The convergence characteristic for the hybrid VSI and WOA for the three case studies (Case 2, Case 3, and Case 4) is presented in Fig. 7. It is clear that WOA converged fast due to decreasing the search space through the fuzzy process applied with the VSI.

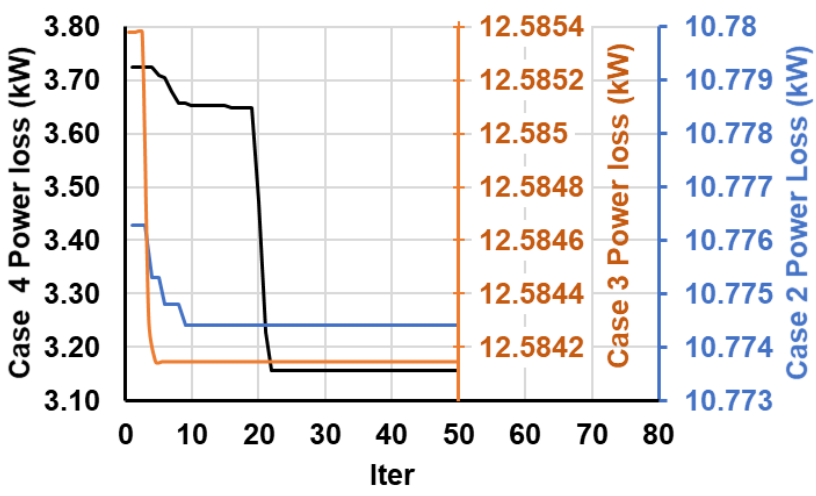

Fig. 7. Convergence characteristics of the WOA for 12-bus at different case studies.

TABle II. DG Allocation in 12- bus System at Different Case Studies

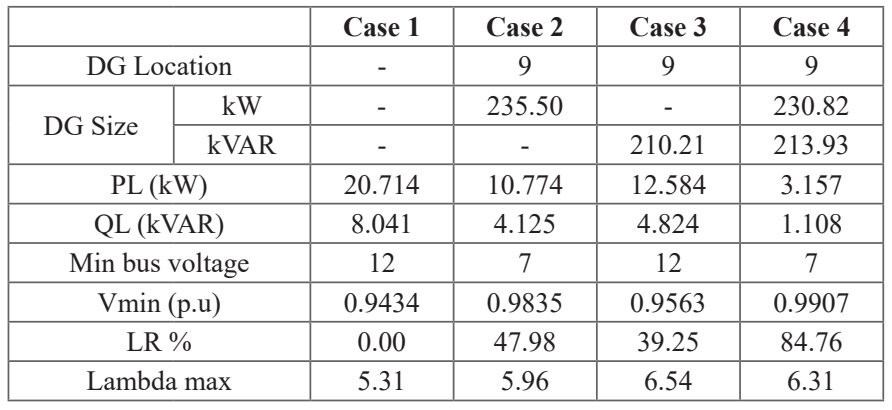

\section{Voltage Stability Assessment}

In this section, the PV curve is obtained with the CPF using the PSAT package to evaluate the voltage stability of the radial distribution system with DG allocation. Fig. 8 shows the PV curves for the four case studies at bus 12 which is the minimum bus voltage. It can observe that in Case 1 the maximum lambda loading is 5.31\%. In Case 2, the loading factor increases to $5.96 \%$, which demonstrates the influence of the active power of the DG. However, the maximum loading lambda is achieved at Case 3 which equals $6.54 \%$ and this is due to the injected DG reactive power. Finally, the impact of the active and reactive power injected by the DG on the PV curve is carried out in Case 4 and the reported Lambda max is $6.31 \%$.

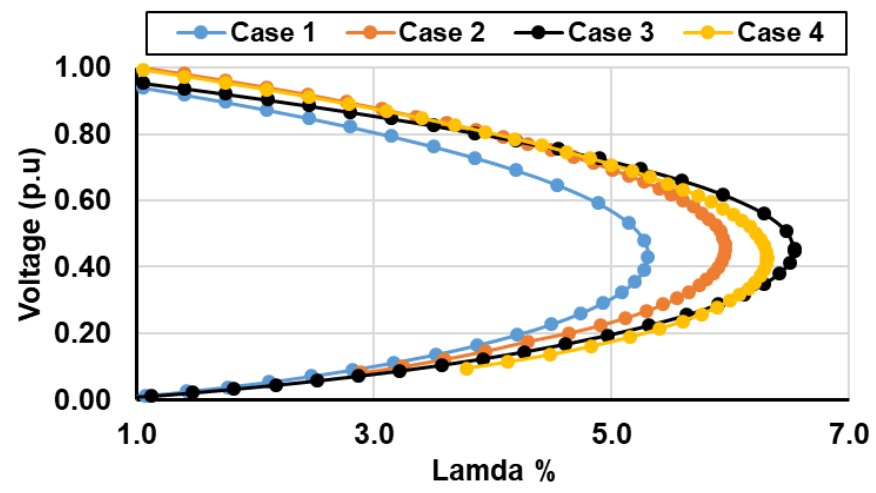

Fig. 8. PV curve for 12-bus at different case studies. 


\section{B. 33-Bus Radial Distribution System}

The second system used to validate the proposed method is the 33-bus radial distribution system. The complete depiction of this test system involves the line and load data that can be obtained in [27]. The fuzzy logic controller with the NVSI and voltage magnitude is applied to this system and the highest candidates' buses are 7 and 30. However, during the search process with the WOA and the updating positions, buses 6 and 30 are found to be the best buses for DG allocation as summarized in Table III.

\section{DG Allocation}

Table III presents the optimal sizes and locations of the three cases of DG allocations. In Case 1, the power loss is $210.986 \mathrm{~kW}$ and it decreases to $111.019 \mathrm{~kW}, 151.365 \mathrm{~kW}$, and $67.855 \mathrm{~kW}$ at Case 2, Case 3, and Case 4, respectively. The voltage profile has a significant enhancement in Case 4 as shown in Fig. 9 where the minimum voltage is reported at bus 18 , which equals 0.9584 p.u.

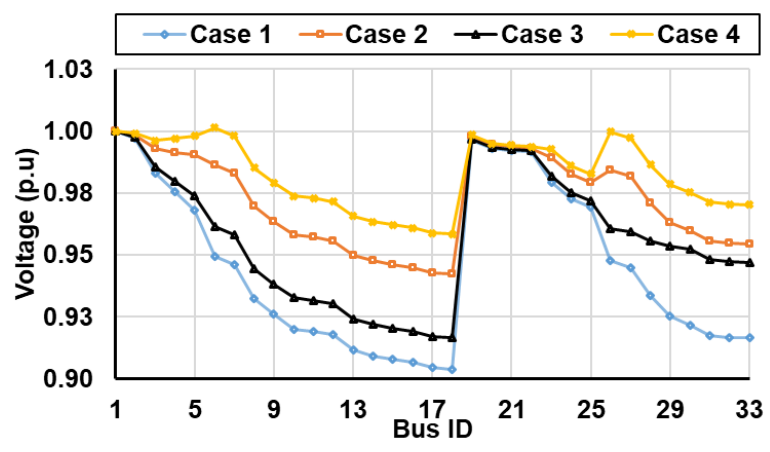

Fig. 9. Voltage profile of 33-bus at different case studies.

The convergence characteristics of the proposed method are displayed in Fig 10. Case 4 needed the highest number of iterations to converge because it searches for the active and reactive powers to minimize the power loss.

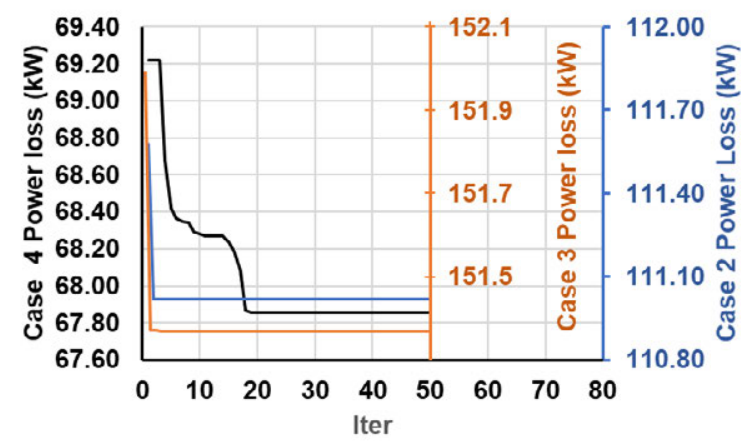

Fig. 10. Convergence characteristics of the WOA for 33-bus at different case studies.

TABle III. DG Allocation in 33-Bus System at Different Case Studies

\begin{tabular}{|c|c|c|c|c|c|}
\hline & & Case 1 & Case 2 & Case 3 & Case 4 \\
\hline \multicolumn{2}{|c|}{ DG Location } & - & 6 & 30 & 6 \\
\hline \multirow{2}{*}{ DG Size } & $\mathrm{kW}$ & - & 2590.21 & - & 2558.92 \\
\hline & kVAR & - & - & 1258.013 & 1760.70 \\
\hline \multicolumn{2}{|c|}{ PL (kW) } & 210.986 & 111.019 & 151.365 & 67.855 \\
\hline \multicolumn{2}{|c|}{ QL (kVAR) } & 143.127 & 81.717 & 103.890 & 54.840 \\
\hline \multicolumn{2}{|c|}{ Min bus voltage } & 18 & 18 & 18 & 18 \\
\hline \multicolumn{2}{|c|}{$\operatorname{Vmin}(\mathrm{p} . \mathrm{u})$} & 0.9038 & 0.9424 & 0.9165 & 0.9584 \\
\hline \multicolumn{2}{|c|}{ LR \% } & 0.00 & 47.38 & 28.26 & 67.84 \\
\hline \multicolumn{2}{|c|}{ Lambda max } & 3.40 & 3.72 & 3.90 & 3.86 \\
\hline
\end{tabular}

\section{Voltage Stability Assessment}

The PV curve for bus 18, which is the minimum bus voltage at Case 1, is exhibited in Fig. 11 in different case studies. From this figure, it can be observed that the highest lambda is achieved at Case 3 which reaches $3.90 \%$ where it was $3.40 \%$ in Case 1 . The lambda max is 3.72 $\%$ and $3.86 \%$ at Case 2 and Case 4 , respectively.

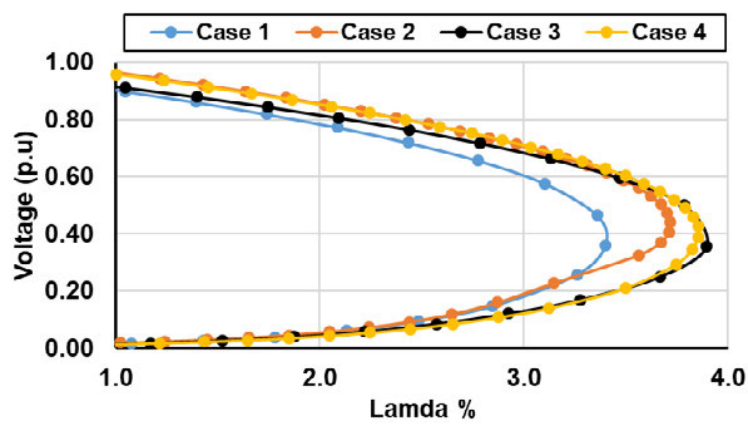

Fig. 11. PV curve for 33-bus at different case studies.

\section{69-Bus Radial Distribution System}

This system consists of 69 radial connected buses and 68 branches, the single line diagram and the line and load data is available in [28]. In this system, the highest order candidate bus obtained by the fuzzy logic controller is bus 61 , hence it is chosen by the WOA to be the optimal location for the DG in the three case studies.

\section{DG Allocation}

Table IV presents the base case results of the 69-bus system where the power loss is $224.95 \mathrm{~kW}$, the reactive power loss is $102.146 \mathrm{kVAR}$, and the minimum voltage is 0.9092 at bus 65 . However, with connected three DG types at three case studies, the active power LR reaches 63.02, 32.43, and 89.71 at Case 2, Case 3, and Case 4, respectively. Also, the voltage profile achieves a significant improvement as shown in Fig. 12. Fig 13 demonstrates the convergence characteristics of the proposed method and it is clear that the WOA converged at a low number of iterations.

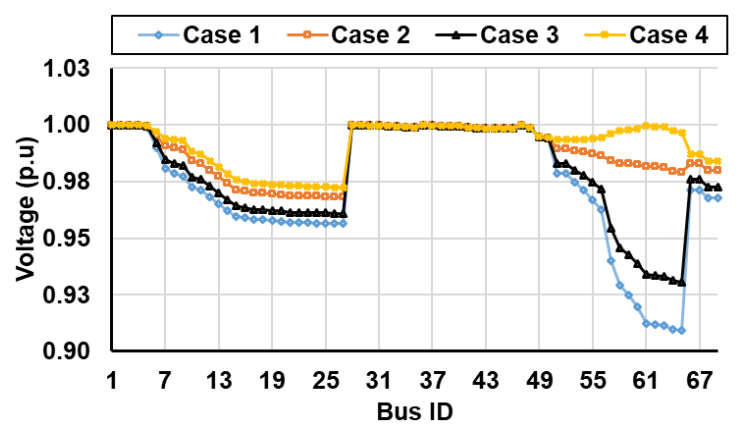

Fig. 12. Voltage profile of 69-bus at different case studies.

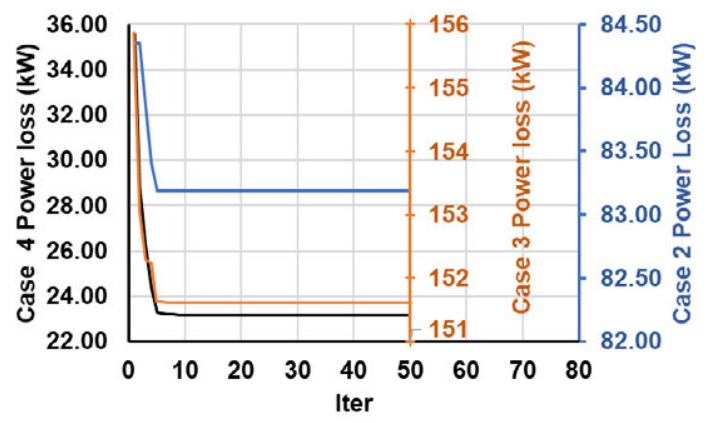

Fig. 13. Convergence characteristics of the WOA for 69-bus at different case studies. 
TABLE IV. DG Allocation in 69- Bus System at Different Case Studies

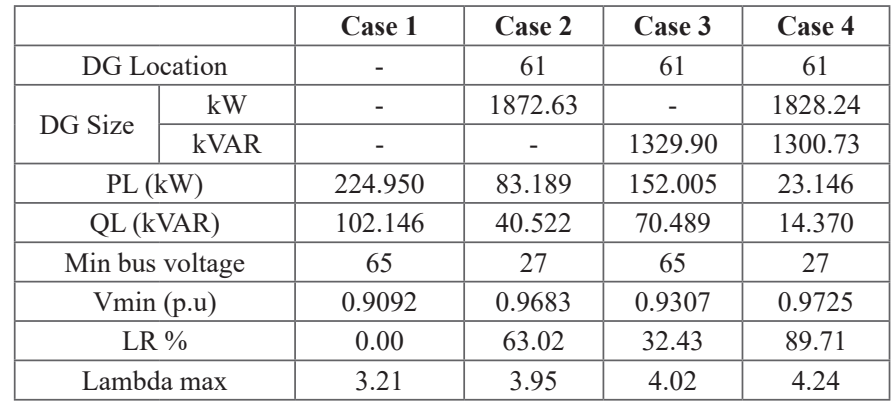

\section{Voltage Stability Assessment}

Fig. 14 reveals the PV curves for bus 65 at different case studies, the highest lambda max is $4.24 \%$ attained at Case 4 where the impact of the DG integration on the voltage stability is clearly assessed using the PV curve.

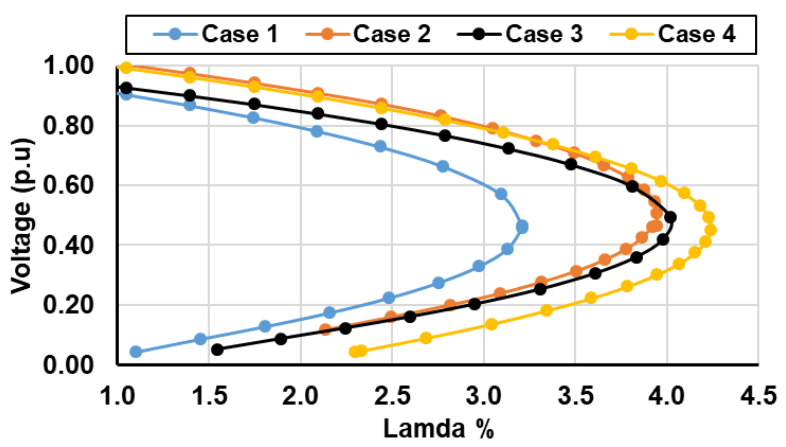

Fig. 14. PV curve for 69-bus at different case studies.

\section{85-Bus Radial Distribution System}

This system considers a large and long radial distribution system. The system includes 85 buses and 84 branches and the overall data can be obtained from [29]. Bus 8 has the highest order weighting based on the fuzzy logic controller so that this bus is considered the optimal location for DG location at the different case studies.

\section{DG Allocation}

Due to the length of this system, the power loss is $315.973 \mathrm{~kW}$ and the lowest voltage is 0.8714 p.u at bus 54 as given in Table V. By applying the proposed VSI and WOA at three DG allocation cases, the Power loss decrease to $175.470, \mathrm{~kW} 180.548 \mathrm{~kW}$, and $62.576 \mathrm{~kW}$ with LR $44.47 \%$, $42.86 \%$, and $80.20 \%$ at Case 2, Case 3, and Case 4 respectively. Also, the voltage at bus 54 increases to 0.9283 p.u, 0.9108 p.u, and 0.9616 p.u at Case 2, Case 3, and Case 4, respectively. The enhancement in the voltage profiles for all buses is presented in Fig. 15.

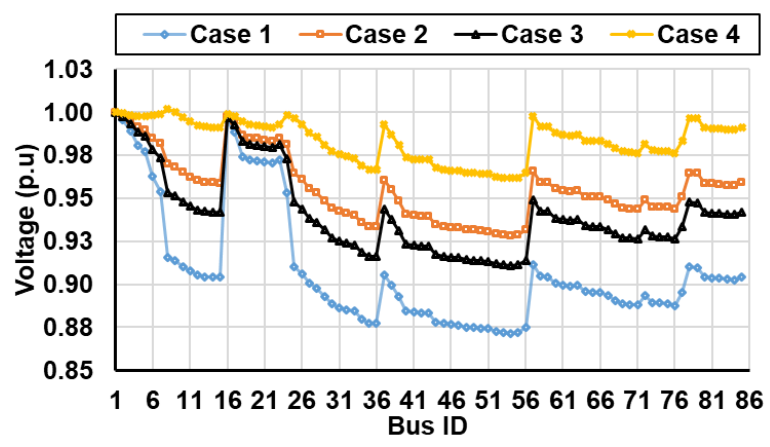

Fig. 15. Voltage profile of 85 -bus at different case studies.
Fig. 16 proves the efficiency of the WOA in allocating the DG at different case studies in the large-scale distribution system with low iteration numbers.

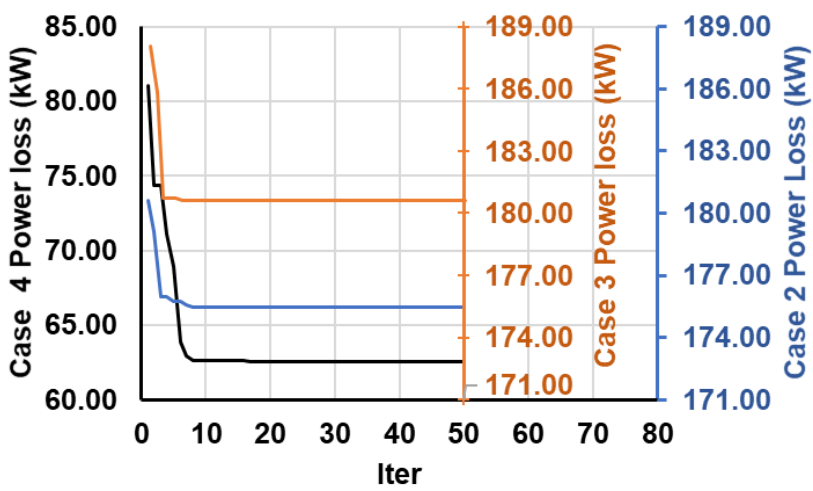

Fig. 16. Convergence characteristics of the WOA for 85-bus at different case studies.

Table V. DG Allocation in 85- Bus System At Different Case Studies

\begin{tabular}{|c|c|c|c|c|c|}
\hline & & Case 1 & Case 2 & Case 3 & Case 4 \\
\hline \multicolumn{2}{|c|}{ DG Location } & - & 8 & 8 & 8 \\
\hline \multirow{2}{*}{ DG Size } & kW & - & 2373.78 & - & 2268.50 \\
\hline & kVAR & - & - & 2332.77 & 2259.11 \\
\hline \multicolumn{2}{|c|}{ PL $(\mathrm{kW})$} & 315.973 & 175.470 & 180.548 & 62.576 \\
\hline \multicolumn{2}{|c|}{ QL (kVAR) } & 198.701 & 104.385 & 107.276 & 27.997 \\
\hline \multicolumn{2}{|c|}{ Min bus voltage } & 54 & 54 & 54 & 54 \\
\hline \multicolumn{2}{|c|}{ Vmin (p.u) } & 0.8714 & 0.9283 & 0.9108 & 0.9616 \\
\hline \multicolumn{2}{|c|}{ LR \% } & 0.00 & 44.47 & 42.86 & 80.20 \\
\hline \multicolumn{2}{|c|}{ Lambda max } & 2.55 & 2.74 & 3.29 & 2.94 \\
\hline
\end{tabular}

2. Voltage Stability Assessment

Similarly, the PV curve for the 85-bus is drawn using the CPF at different case studies of DG integration as exhibited in Fig. 17. The base case lambda max of this system is $2.55 \%$ and this value increased to $2.74 \%$ when connecting DG at bus 8 with $2373.78 \mathrm{~kW}$. Furthermore, a considerable increase in the lambda is accomplished at Case 2 with $2332.77 \mathrm{kVAR}$ connected on bus 8 . Finally, at Case 4 the lambda reaches $2.94 \%$ with $2268.5 \mathrm{~kW}$ and $2259.11 \mathrm{kVAR}$ at the same bus.

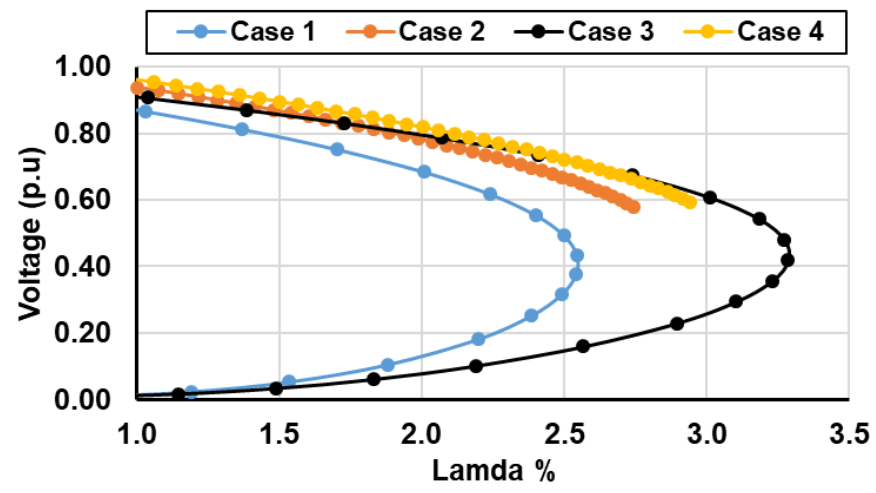

Fig. 17. PV curve for 85 -bus at different case studies.

\section{E. Result comparison}

To demonstrate the efficiency of the developed method, a comparison is performed with other optimization techniques mentioned in the literature such as; analytical technique [15], PSO [12], CS [21], 
NSGA-II [22]. As presented in Table VI, the proposed method has the highest LR compared to all techniques. However, for the maximum loading factor the proposed method gives the highest loading factor in 12 - bus that equals $6.31 \%$. Also, the same lambda max in 69-bus is given by the proposed method and NSGA II which reaches $4.24 \%$. The maximum loading factor in 33-bus is given by the CS algorithm. In addition, for 85 -bus the NSGA II has the maximum lambda $2.94 \%$.

TABLE VI. Result Comparison with Other Optimization Techniques

\begin{tabular}{|c|c|c|c|c|c|}
\hline Method & & 12-bus & 33-bus & 69-bus & 85-bus \\
\hline \multirow{4}{*}{$\begin{array}{c}\text { Proposed } \\
\text { method } \\
\text { VSI and } \\
\text { WOA }\end{array}$} & DG location & 9 & 6 & 61 & 8 \\
\hline & DG size (kVA) & 314.71 & 3106.14 & 2243.73 & 3201.5 \\
\hline & LR \% & 84.76 & 67.84 & 89.71 & 80.20 \\
\hline & Lambda max \% & 6.31 & 3.86 & 4.24 & 2.94 \\
\hline \multirow{4}{*}{$\begin{array}{c}\text { Analytical } \\
\text { technique } \\
{[15]}\end{array}$} & DG location & 9 & 6 & 61 & 8 \\
\hline & DG size $(\mathrm{kVA})$ & 227.15 & 2490.78 & 1807.8 & 22088.6 \\
\hline & LR \% & 47.95 & 47.31 & 62.95 & 44.28 \\
\hline & Lambda max \% & 5.92 & 3.70 & 3.92 & 2.88 \\
\hline \multirow{4}{*}{$\begin{array}{c}\text { NSGA-II } \\
{[22]}\end{array}$} & DG location & 8 & 7 & 61 & 25 \\
\hline & DG size $(\mathrm{kVA})$ & 435 & 3715 & 2663.8 & 2484.5 \\
\hline & LR \% & 33.97 & 35.92 & 53.8 & 42.75 \\
\hline & Lambda max \% & 6.08 & 3.88 & 4.24 & 2.96 \\
\hline \multirow{4}{*}{ PSO [12] } & DG location & 9 & 7 & 61 & \\
\hline & DG size $(\mathrm{kVA})$ & 253.9 & 2895.1 & 2026.4 & \\
\hline & LR \% & 47.7 & 45.55 & 62.65 & \\
\hline & Lambda max \% & 6.03 & 3.78 & 4.03 & \\
\hline \multirow{4}{*}{ CS [21] } & DG location & & 61 & & \\
\hline & DG size (kVA) & & 2200 & & \\
\hline & LR \% & & 62.8 & & \\
\hline & Lambda max \% & & 4.06 & & \\
\hline
\end{tabular}

V. Conclusion

In this paper, an assessment of power systems voltage stability with DG integration using CPF has been presented. A hybrid between VSI and WOA has been developed to place the DG in the radial distribution system. NVSI and voltage magnitude at each node has been modeled with the fuzzy logic controller to find the candidate buses which are the most sensitive buses to allocate the DG. Finally, the optimal size and location have been achieved using the WOA. The developed method has been tested using the 12,33,69 and 85 bus radial distribution systems. To present the effectiveness of the developed method, a comparison with existing techniques has been accomplished. The obtained results proved the efficiency and capability of the developed optimization technique for selecting the optimal DG location and size using the voltage stability index. In addition, a significant increase in the loadability has been obtained with integrating DG that injects both active and reactive powers. The extended work of this paper is to improve the exploration and exploitation phases of the WOA by hybridizing with other metaheuristic optimization techniques.

\section{ACKNOWLEDGMENT}

The authors gratefully acknowledge the contribution of the NSFC (China)-ASRT (Egypt) Joint Research Fund, Project No. 51861145406 for providing partial research funding to the work reported in this research.

\section{REFERENCES}

[1] J. Modarresi, E. Gholipour, and A. Khodabakhshian, "A comprehensive review of the voltage stability indices," Renewable and Sustainable
Energy Reviews, vol. 63, pp. 1-12, 2016.

[2] A. Sode-Yome and N. Mithulananthan, "Comparison of shunt capacitor, SVC and STATCOM in static voltage stability margin enhancement," International Journal of Electrical Engineering Education, vol. 41, no. 2, pp. 158-171, 2004.

[3] I. Musirin and T. A. Rahman, "Novel fast voltage stability index (FVSI) for voltage stability analysis in power transmission system," in Research and Development, 2002. SCOReD 2002. Student Conference on, 2002: IEEE, pp. 265-268.

[4] W. Ahmed, A. Selim, S. Kamel, J. Yu, and F. Jurado, "Probabilistic Load Flow Solution Considering Optimal Allocation of SVC in Radial Distribution System," International Journal of Interactive Multimedia and Artificial Intelligence, vol. 5, no. 3, pp. 152-161, 2018.

[5] M. Abdel-Nasser, K. Mahmoud, and H. Kashef, "A Novel Smart Grid State Estimation Method Based on Neural Networks," International Journal of Interactive Multimedia and Artificial Intelligence, vol. 5, no. 1, pp. 92-100, 2018.

[6] C. Reis and F. M. Barbosa, "A comparison of voltage stability indices," in Electrotechnical Conference, 2006. MELECON 2006. IEEE Mediterranean, 2006: IEEE, pp. 1007-1010.

[7] V. Murty and A. Kumar, "Optimal placement of DG in radial distribution systems based on new voltage stability index under load growth," International Journal of Electrical Power \& Energy Systems, vol. 69, pp. 246-256, 2015.

[8] T. J. Overbye and C. L. DeMarco, "Improved techniques for power system voltage stability assessment using energy methods," IEEE Transactions on Power Systems, vol. 6, no. 4, pp. 1446-1452, 1991.

[9] E. Vaahedi, J. Tamby, Y. Mansour, W. Li, and D. Sun, "Large scale voltage stability constrained optimal VAr planning and voltage stability applications using existing OPF/optimal VAr planning tools," IEEE Transactions on Power Systems, vol. 14, no. 1, pp. 65-74, 1999.

[10] R. Al Abri, E. F. El-Saadany, and Y. M. Atwa, "Optimal placement and sizing method to improve the voltage stability margin in a distribution system using distributed generation," IEEE transactions on power systems, vol. 28, no. 1, pp. 326-334, 2013.

[11] M. Aman, G. Jasmon, A. Bakar, and H. Mokhlis, "A new approach for optimum simultaneous multi-DG distributed generation Units placement and sizing based on maximization of system loadability using HPSO (hybrid particle swarm optimization) algorithm," Energy, vol. 66, pp. 202215, 2014.

[12] M. M. Aman, G. B. Jasmon, A. H. A. Bakar, and H. Mokhlis, "A new approach for optimum DG placement and sizing based on voltage stability maximization and minimization of power losses," Energy Conversion and Management, vol. 70, pp. 202- 210, 2013.

[13] M. P. HA, P. D. Huy, and V. K. Ramachandaramurthy, "A review of the optimal allocation of distributed generation: Objectives, constraints, methods, and algorithms," Renewable and Sustainable Energy Reviews, vol. 75, pp. 293-312, 2017.

[14] Ehsan, Ali, and Q. Yang. "Optimal integration and planning of renewable distributed generation in the power distribution networks: A review of analytical techniques," Applied Energy 210 (2018): 44-59.

[15] T. Gözel and M. H. Hocaoglu, "An analytical method for the sizing and siting of distributed generators in radial systems," Electric Power Systems Research, vol. 79, pp. 912-918, 2009.

[16] D. Q. Hung and N. Mithulananthan, "Multiple distributed generator placement in primary distribution networks for loss reduction," IEEE Transactions on industrial electronics, vol. 60, no. 4, pp. 1700-1708, 2013.

[17] V. Murty and A. Kumar, "Optimal placement of DG in radial distribution systems based on new voltage stability index under load growth," International Journal of Electrical Power \& Energy Systems, vol. 69, pp. 246-256, 2015.

[18] R. K. Singh and S. K. Goswami. "Optimum siting and sizing of distributed generations in radial and networked systems," Electric Power Components and Systems, vol. 37, no. 2, pp. 127-145, 2009.

[19] K. Satish, V. Kumar, and B. Tyagi. "Optimal placement of different type of DG sources in distribution networks," International Journal of Electrical Power \& Energy Systems, vol. 53, pp. 752-760, 2013.

[20] Moravej, Zahra, and A. Akhlaghi. "A novel approach based on cuckoo search for DG allocation in distribution network," International Journal of Electrical Power \& Energy Systems, vol. 44, no. 1, pp. 672-679, 2013. 
[21] Tan, W. S., et al. "Allocation and sizing of DG using cuckoo search algorithm," 2012 IEEE international conference on power and energy (PEcon). IEEE, 2012.

[22] Mohammedi, R. D., et al. "Optimal DG placement and sizing in radial distribution systems using NSGA-II for power loss minimization and voltage stability enhancement," International Review of Electrical Engineering, vol. 8, no. 06, 2013.

[23] A. Selim, S. Kamel, and F. Jurado, "Voltage Profile Improvement in Active Distribution Networks Using Hybrid WOA-SCA Optimization Algorithm," in 2018 Twentieth International Middle East Power Systems Conference (MEPCON), 2018: IEEE, pp. 1064-1068.

[24] A. Selim, S. Kamel, and F. Jurado, "Hybrid Optimization Technique for Optimal Placement of DG and D-STATCOM in Distribution Networks," in 2018 Twentieth International Middle East Power Systems Conference (MEPCON), 2018: IEEE, pp. 689-693.

[25] S. Mirjalili and A. Lewis, "The whale optimization algorithm," Advances in Engineering Software, vol. 95, pp. 51-67, 2016.

[26] P. R. Babu, C. Rakesh, M. N. Kumar, G. Srikanth, and D. P. Reddy, "A novel approach for solving distribution networks," in India Conference (INDICON), 2009 Annual IEEE, 2009: IEEE, pp. 1-5.

[27] R. Rajaram, K. S. Kumar, and N. Rajasekar, "Power system reconfiguration in a radial distribution network for reducing losses and to improve voltage profile using modified plant growth simulation algorithm with Distributed Generation (DG)," Energy Reports, vol. 1, pp. 116-122, 2015.

[28] M. E. Baran and F. F. Wu, "Optimal sizing of capacitors placed on a radial distribution system," Power Delivery, IEEE Transactions on, vol. 4, pp. 735-743, 1989

[29] D. Das, D. P. Kothari, and A. Kalam, "Simple and efficient method for load flow solution of radial distribution networks," International Journal of Electrical Power \& Energy Systems, vol. 17, pp. 335-346, 1995.

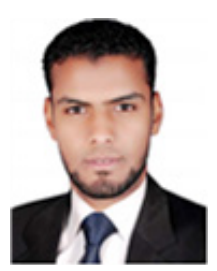

\section{Ali Selim}

Ali Selim received his BSc and MSc degrees in Electrical Engineering from Aswan University, Egypt, in 2010 and 2016 respectively. He is currently a Ph.D. student in the Department of Electrical Engineering at the University of Jaén (Universidad de Jaén), Spain. His research interests include mathematical optimization, planning, and control of power systems, renewable energies, energy storage, and smart grids.

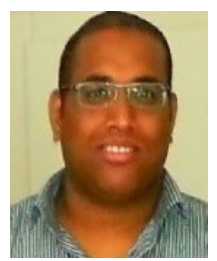

\section{Salah Kamel}

Salah Kamel received the international Ph.D. degree from University of Jaen, Spain (Main) and Aalborg University, Denmark (Host) in Jan. 2014. He is an Assistant Professor in the Electrical Engineering Department, Aswan University. Also, He is a Leader for a power systems research group in the Advanced Power Systems Research Laboratory (APSR Lab), Aswan, Egypt. He is currently a Postdoctoral Research Fellow in State Key Laboratory of Power Transmission Equipment and System Security and New Technology, School of Electrical Engineering, Chongqing University, Chongqing, China. His research activities include power system modeling, analysis and simulation, and applications of power electronics to power systems and power quality.

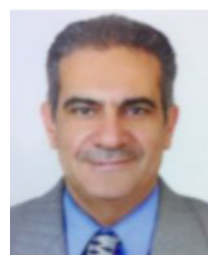

\section{Loai. S. Nasrat}

Loai. S. Nasrat is a professor at Aswan University, Faculty of Eng., Elect. P\&M Department. He has been actively involved in both basic and applied research in the area of HV engineering. His research interests include HV insulators, Nano polymeric materials, HV cables insulations, Aged oil transformer, and environmental studies. Author and coauthor of more than 60 papers on $\mathrm{HV}$ polymeric insulating materials, Nano insulating materials published in technical journals and proceedings of national and international conferences. Dr. Loai is a member of the Egyptian Sub-Committee of CIGRE

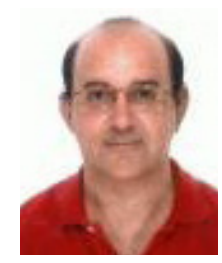

Francisco Jurado

Francisco Jurado obtained the MSc and Ph.D. degrees from the UNED, Madrid, Spain, in 1995 and 1999 respectively. $\mathrm{He}$ is Full Professor at the Department of Electrical Engineering of the University of Jaén, Spain. His research activities have focused on two topics: power systems and renewable energy. 